\title{
Use of laser scanner technology as part of the slope stability risk management strategy at Letšeng diamond mine
}

\author{
N Lefu Letšeng Diamonds (Pty) Ltd, Lesotho \\ V Nokwe Maptek, South Africa
}

\begin{abstract}
The stability of slopes in open pit mines is an issue of great concern because of the detrimental consequences that instabilities can cause. Therefore, stringent systematic slope stability assessment and risk management are imperative to ensure the safe and continuous economic operation of these mines. Laser scanning technology is the most advanced method in geodesy and emerged as an indispensable tool in open pit data collection, interpretation and analysis. In 2018, Letšeng acquired a Maptek XR3 laser scanner for volumetric surveys, geological and geotechnical data collection and analysis, as well as tactical and strategic slope deformation monitoring. Letšeng diamond open pit mine is the highest altitude diamond mine in the world at around 3,100 m above sea level, where two kimberlite pipes are mined as successive pushbacks. The mine is in the northern region of Lesotho, within the Drakensberg Formation of the Karoo Supergroup. The article discusses the use of the laser scanning method as part of a slope stability management strategy at Letšeng. The first part discusses geological and geotechnical data collection, detailed structural analysis and detection of potentially unstable rock masses on the pit slope. The second part discusses slope reconciliation and slope deformation monitoring.
\end{abstract}

Keywords: laser scanning, slope stability, risk management

\section{$1 \quad$ Introduction}

\subsection{Background}

The primary purpose of any open pit mine is to minimise the volume of waste rock excavated while providing an economic and safe excavation suitable for its intended function (Parisean 2006). Maintaining pit slopes that are as steep as possible is of vital importance to reduce waste stripping, as this will have a positive direct consequence on the economy of the mining operation. However, the benefit of slope steepening can be negated by slope failure. The design of pit slopes is not only controlled by economic factors but geotechnical conditions as well. Slope instability is directly dependent on the geological structure, including the variability of the geotechnical and hydrogeological conditions (Barzanic 2018). Prevention of negative effects of phenomena occurring on the rock mass is based on systematic and detailed assessment of geological and geotechnical controls and maintaining a safe amount of risk that determines the instability of open pit excavations (Strang 2010). Discontinuities tend to play a significant role in slope stability assessment as their occurrence and characterisation have a vital influence upon the stability of rock pit slopes (Bye \& Bell 2001).

Geodetic and geotechnical monitoring plays a vital role in preventing and forecasting slope instability threat (Barzanic 2018). Monitoring is an important element of the risk management, which includes both the identification of threats as well as their assessment and characterisation. 3D laser scanning technology is the most innovative and advanced method in geodesy and has recently emerged as an indispensable tool in open pit survey and geotechnical applications. Laser scanners provide fast and efficient detailed and highly accurate 3D data and can retrieve comprehensive information on the rock slopes, especially for areas of difficult access. Today, detailed terrestrial laser scanner surveys are used in several geological environments and with different purposes such as volumetric measurements, topographic mapping, geological and geotechnical mapping, slope deformation monitoring, excavation compliance and others (Slob \& Hack 2004; 
Oppikoffer et al. 2009; Abellan et al. 2009). Currently, several types of laser scanners are in use (Beraldin 2004; Nguyen et al. 2011). For geotechnical applications, especially for morphological studies and long-range applications, laser scanners using time-of-flight technology are the most suitable. In 2018 Letšeng acquired a Maptek XR3 laser scanner for volumetric surveys, geological and geotechnical data collection and analysis, as well as tactical and strategic slope deformation monitoring. The article discusses the use of the laser scanning method as part of a slope stability management strategy at Letšeng.

Letšeng diamond mine (LDM) is an open pit mine located approximately $70 \mathrm{~km}$ from Mokhotlong camp in the northern region of Lesotho (Figure 1). The mine lies at the heart of the Maluti Mountains at an altitude of 3,100 $\mathrm{m}$ above sea level, making it one of the highest altitude diamond mines in the world (Bowen et al. 2009). The mine is owned by Letšeng Diamonds (Pty) Ltd which has two shareholders; Gem Diamonds owns $70 \%$ and the Government of Lesotho owns the remaining $30 \%$. The mine is an open pit operation where two kimberlite pipes, the Main Pit and the Satellite Pit, bearing low-grade ore (averaging under two carats per hundred tonnes) are currently being mined as consecutive pushbacks. The mine is, however, famous for the production of large, top-quality diamonds and has the highest percentage of large $(+10.8$ carat) diamonds of any kimberlite mine. It is also the highest dollar value per carat kimberlite diamond mine in the world. The mine employs conventional mining, consisting of drilling and blasting, loading, hauling and other supplementary activities.

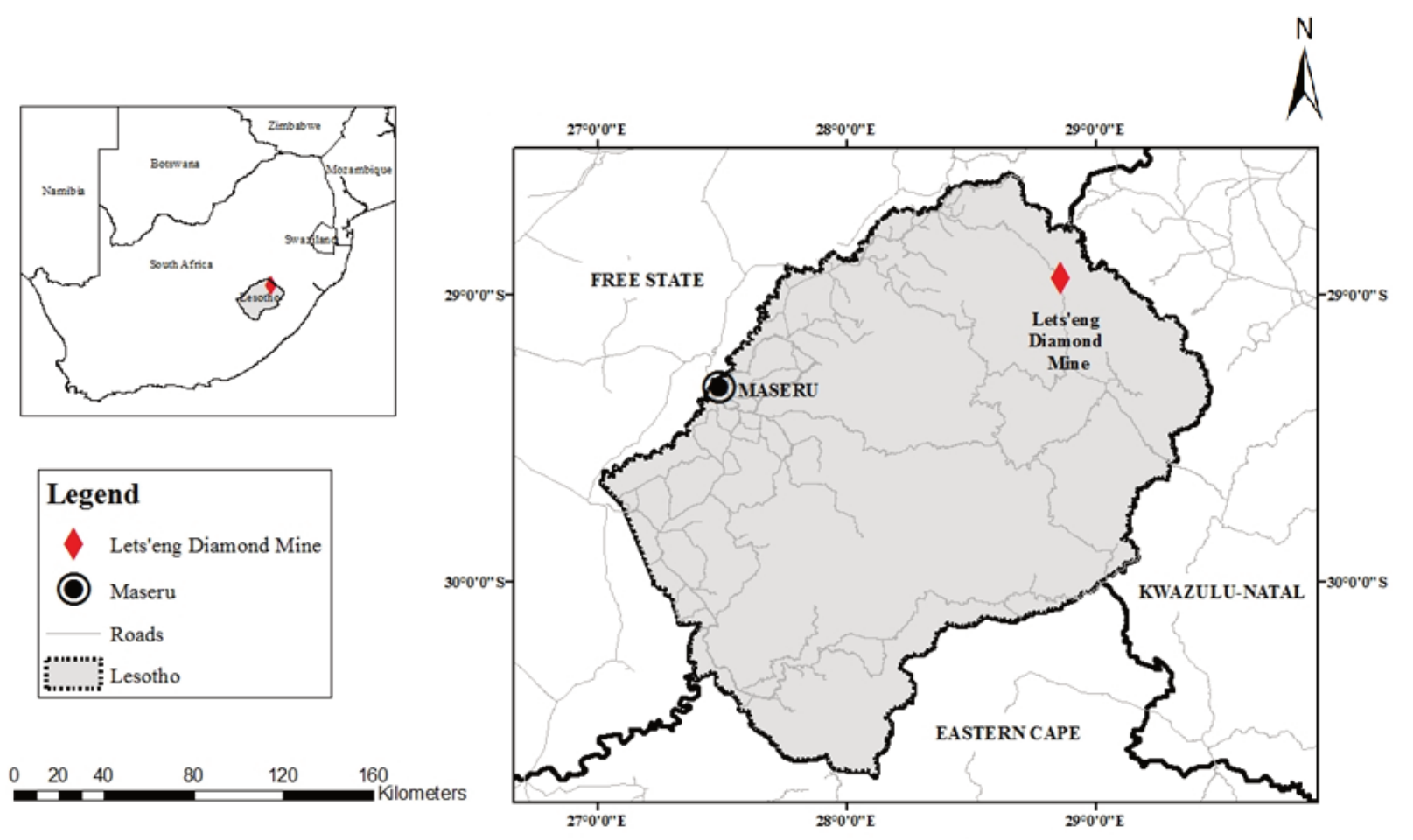

Figure 1 Locality map of Letšeng diamond mine

\subsection{Geology}

Letšeng comprises two adjacent pipes named Main Pipe and Satellite Pipe. The pipes are age dated at ca. 90Ma (Stanley et al. 2015) and were emplaced into ca. 1,800-2,000 m thick basalt of the Lesotho (Drakensberg Group) Formation of the Karoo Supergroup. The basalt is underlain by sandstones and siltstones of the Clarens Formation although xenoliths of these rocks are only rarely observed in the kimberlite.

Main Pipe is dominated by one phase of kimberlite termed K1 (previously KMain), which comprises relatively uniform Kimberley-type pyroclastic kimberlite (Scott Smith et al., 2013) containing large megaxenoliths of basalt and a minor but distinctive population of small white basement macroxenoliths. Satellite Pipe is also dominated by KPK kimberlite that similarly contains abundant basalt xenolith material ranging from micro- to megaxenoliths. The pipe is sub-divided into two main kimberlite domains: Southern Volcaniclastic 
Kimberlite and Northern Volcaniclastic Kimberlite, separated by a sharp, steep cross-cutting internal contact (Hetman et al., 2018).

\section{3D laser scanning technology}

The laser scanning technology and operating principles can be separated into triangulation scanners, timeof-flight scanners and phase-based scanners (Rosser et al., 2005). The most suitable operating principle for morphological and geological studies is time-of-flight scanners for reflectorless and contactless acquisition of point clouds for any topography due to their ability to operate from great distances (Sturzenegger and Stead, 2009). Time-of-flight laser scanning calculates the coordinates in 3D space of its surrounding based on the amount of time it takes a single laser signal to return to the device for being reflected (Bohler and Marbs, 2002).

The laser scanner used at Letšeng to acquire data and for slope deformation is a Maptek XR3 scanner which has an operating maximum range of $2,400 \mathrm{~m}$ off the reflector with an accuracy of $5 \mathrm{~mm}, 4 \mathrm{~mm}$ with repeatability. The acquisition rate is $200 \mathrm{Khz}$ (quickest but reduces range), $100 \mathrm{Khz}$ (medium range) and $50 \mathrm{Khz}$ (longer range but takes more time). Table 1 and Figure 2 show the laser spot size and spacing for different scanning resolutions. As shown in the table, the density of the point cloud increases with an increase in resolution. Resolution 8 provides dense and detailed point cloud as compared to resolution 1 (Figure 3). The choice of the resolution is dependent on the quality of data required and the application of the acquired point cloud. For geotechnical mapping scans $100 \mathrm{Khz}$ at between $100 \mathrm{~m}$ to $200 \mathrm{~m}$ at resolution 8 is used, while resolution 2 is applicable for topographic mapping and volumetric surveys. The scanner has a built-in 147-megapixel camera that takes true colour images as additional quantitative information for the terrestrial laser scan. Clear and detailed scans are done by colouring point cloud data with RGB values from the digital camera (Figure 4).

The Maptek laser scanner can be mounted on a vehicle for stop-go or continuous survey, it can also be mounted on a tripod. The tripod setup requires two known points for referencing, i.e. the scan position and the backsight position for georeferencing. These coordinates can be entered directly on the scan controller before scanning or on the software during processing. The camera settings are then adjusted to the atmospheric conditions at the time of scanning and the acquisition speed and point density (resolution) are then selected. The Maptek XR3 laser scanner is ideal for various applications including:

- Topographic mapping.

- Volumetric measurements.

- Stability monitoring and rockfall analysis.

- Design conformance.

- Blast analysis.

- Geological and geotechnical mapping.

- Kinematic analysis.

The main advantages of the laser scanning protocol in comparison with traditional geodesy techniques consist of direct, quick and detailed mapping of the object's geometry in 3D. The laser scanning technology provides cost reduction and significantly faster data processing (Bazarnik 2018). 
Table 1 Spot spacing at different resolutions (Maptek 2019)

\begin{tabular}{|c|c|c|c|}
\hline Resolution & Spot diameter & Spot spacing & Visual representation \\
\hline \multirow[t]{2}{*}{ RES 1} & $218 \mathrm{~mm}$ & Horizontal: 1,745 mm & \\
\hline & & Vertical: 873 mm & \\
\hline RES 2 & $218 \mathrm{~mm}$ & $873 \mathrm{~mm}$ & \\
\hline RES 4 & $218 \mathrm{~mm}$ & $436 \mathrm{~mm}$ & ) \\
\hline RES 8 & $218 \mathrm{~mm}$ & $218 \mathrm{~mm}$ & \\
\hline RES 16 & $218 \mathrm{~mm}$ & 109 mm & \\
\hline
\end{tabular}

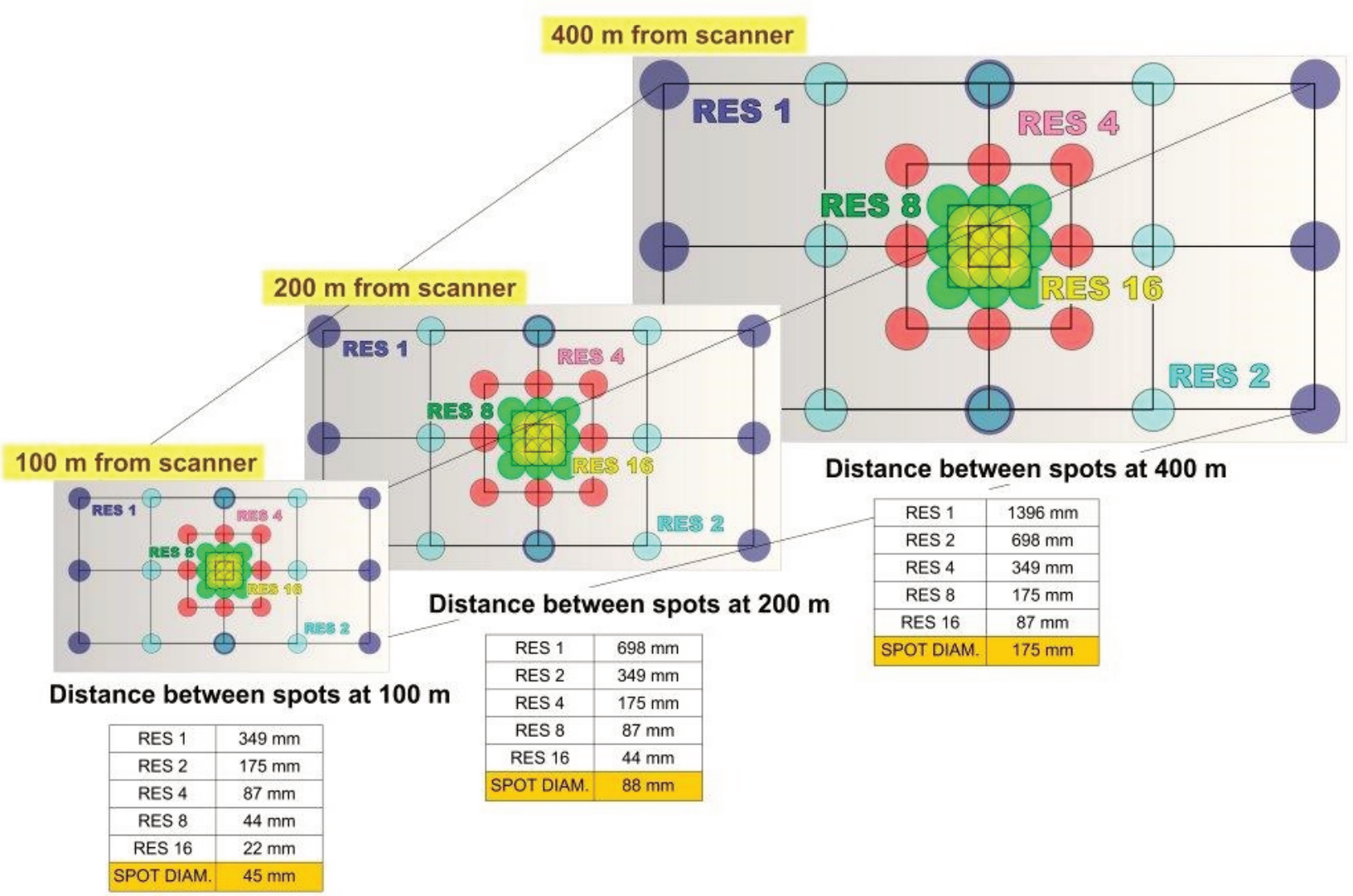

Figure 2 Influence of distance on point cloud density (Maptek 2019) 


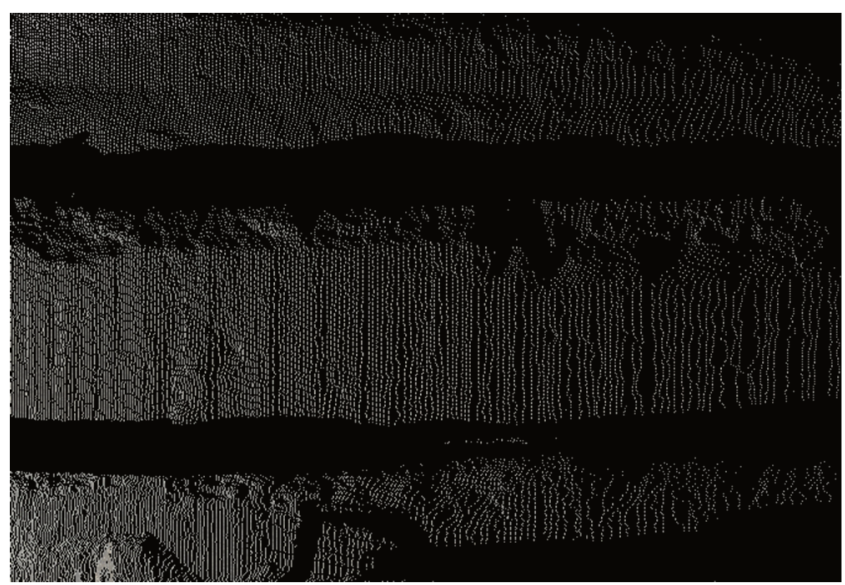

(a)

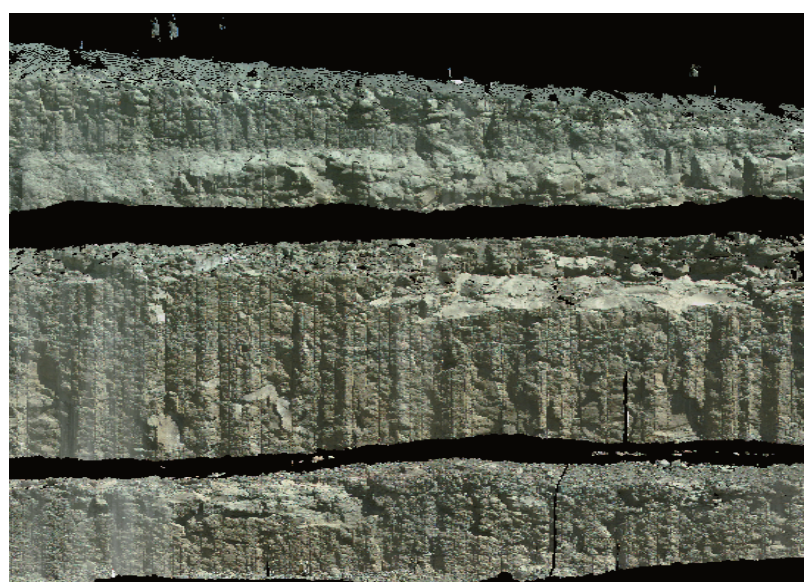

(b)

Figure 3 Point cloud captured by laser scanner at Letšeng Mine. (a) Resolution 1 point cloud; and (b) Resolution 8 point cloud

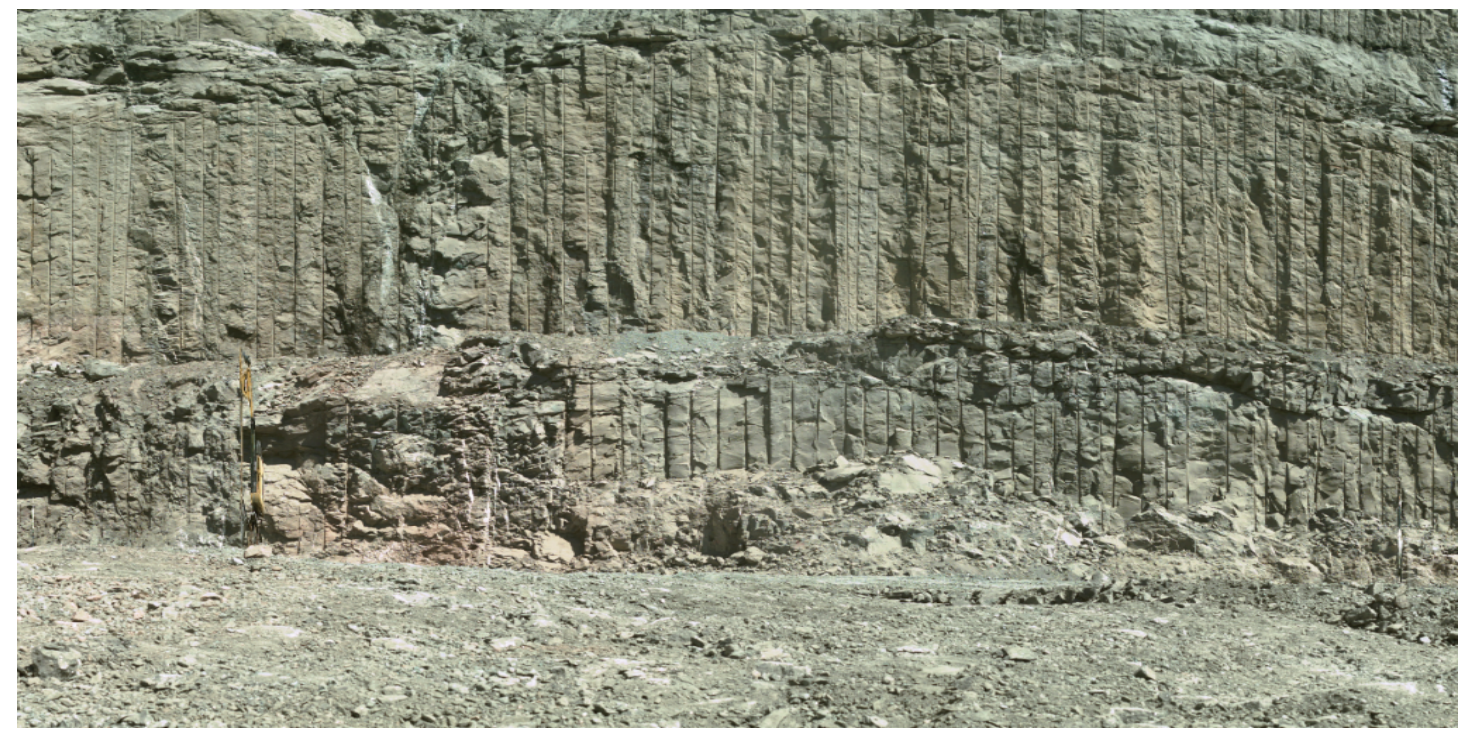

Figure 4 High-resolution photograph captured by the laser scanning system coincident with scanning

\section{Geotechnical data collection and analysis}

\subsection{Discontinuity survey}

The stability of rock slopes is often significantly influenced by the geological defects. Therefore, the assessment of geological structures is an essential part of rock slope stability analysis and slope management. During field survey, it is common practice to measure the geometry of the discontinuities such as orientation, roughness and location (International Society for Rock Mechanics 1978) using standardised methods like scanline surveys or window mapping (Priest 1993). However, the manual sampling and measuring techniques present several downsides which are perfectly supplemented by the introduction of laser scanner technology. Obvious disadvantages include sampling bias due to restricted access to the rock faces, and they are time-consuming and labour intensive (Slob et al. 2005). The use of laser scanning reduces the bias and the measurements are not influenced by the magnetic conductivity of the rocks. This technology should, however, not be considered a replacement of manual sampling but a good supplement and improvement in data collection and processing.

In addition to the traditional scanline and window mapping techniques, the Maptek XR3 laser scanning has become one of the significant techniques that are used for Letšeng discontinuity survey. The geotechnical 
data acquisition is conducted at several scales and distances, so it is necessary to plan for good face coverage, accuracy and precision mapping, scan resolution and the set-up of the scanner (Buckley et al. 2008; Sturzenegger \& Stead 2009). The geotechnical data analysis requires detailed and dense point cloud data and therefore, resolution 8 or resolution 16 are usually used at the mine and the choice is dictated by the distance from the mapped face. Orthogonal setup of the scanner to the mapped face is preferred, the scanner must be at least $100 \mathrm{~m}$ from the face and the change of positions is done to avoid occlusions. A simple tripod setup is done and two known survey points are used for backlighting. The integration of 3D spatial data with $2 \mathrm{D}$ visual data creates spatially accurate representation of the surface topology of the rock. The 3D laser scanner mapping is fast and efficient as it creates a high-resolution point cloud covering large areas in several minutes. Discontinuity properties which include orientation, spacing, surface roughness and persistence can be determined remotely and accurately over long distances and in areas where access is difficult or unsafe.

The dataset is computed using Maptek software PointStudio (Maptek 2020a) that has built-in geotechnical tools. The scans downloaded from the scanner controller are imported into PointStudio together with the reference points. The reference points and the scan files must have the same name. The scans are then registered to the reference points and all scans can be georeferenced at the same time. Filtering of trucks, vegetation, snow, dust, etc. follows to clean up the data. After cleaning the data, a complex 3D surface can be created using a feature size of $5 x$ the point spacing; this is required to perform some functions even though mapping of joints can be achieved by mapping directly from the points or connected points. The data is now ready for geotechnical mapping. Figure 5 shows the simplified data processing workflow.

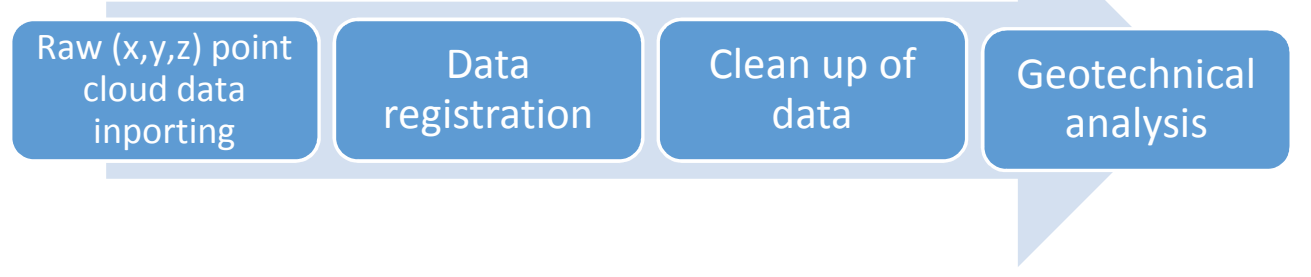

Figure 5 Simplified data processing workflow chart

\subsection{Structural analysis}

From the 3D model, discontinuity characterisation is achieved by using the PointStudio geotechnical module that is designed specifically for geotechnical mapping and analysis. Various methods for extracting discontinuity data are used. These methods include automated techniques that examine orientation trends and a semi-automated method that depends on user structural interpretations of specific features. With the manual point cloud analysis, the geotechnical engineer has the same control that they would have in the field, with the added benefit that the readings will not be restricted to reachable and safe faces only. On the other hand, the automated method is still beneficial because it is quick and produces more data and reduces the potential human influence of the geotechnical engineer. When using the automated method, every visible joint plane within the scan is assessed and characterised. Figure 6 shows the two mapped faces. The orientations of the geological defects are then plotted on the stereonet to analyse and determine discontinuity orientations and major joint set (Figure 7 (a)). The data can also be exported as a csv file for subsequent importation into rock mass analysis software such as DIPS (Figure 7(b)). Both the Maptek stereonet and DIPS show two major joint sets with orientations, 89/184 and 84/072.

PointStudio allows for the accurate measurement of surface roughness through built-in geotechnical tools. The tool divides the selected surface into grids depending on the user's preference. The grid is established in such a way that it groups surfaces that have almost the same amplitude of the irregularities. The results are then used to determine joint roughness coefficient (JRC) from the Barton \& Bandis (1982) JRC chart. Figure 8(a) shows the joint surface plane where roughness is being determined while Figure 8 (c) shows the cross-sections which are compared with JRC chart for JRC estimation. 


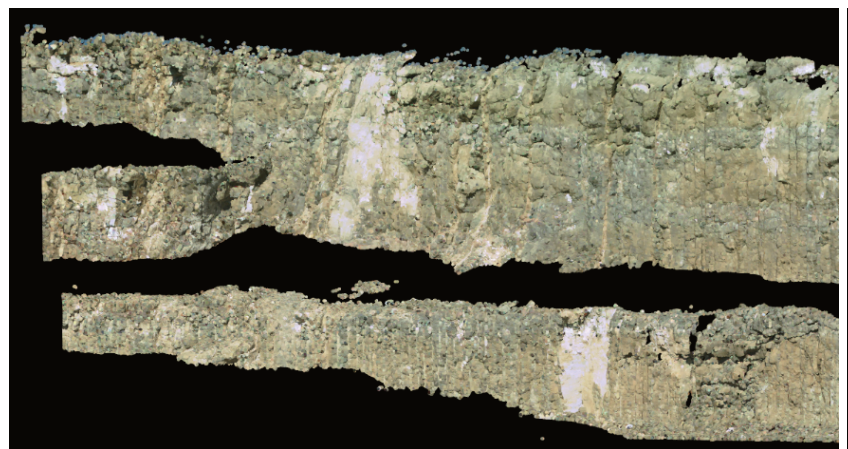

(a)

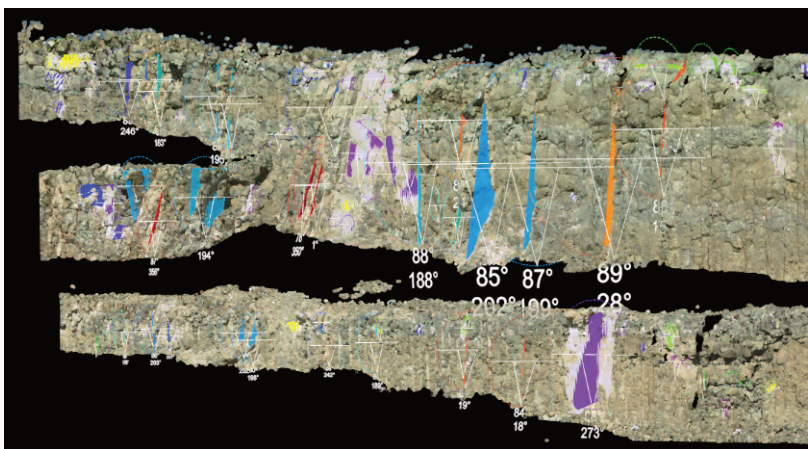

(b)

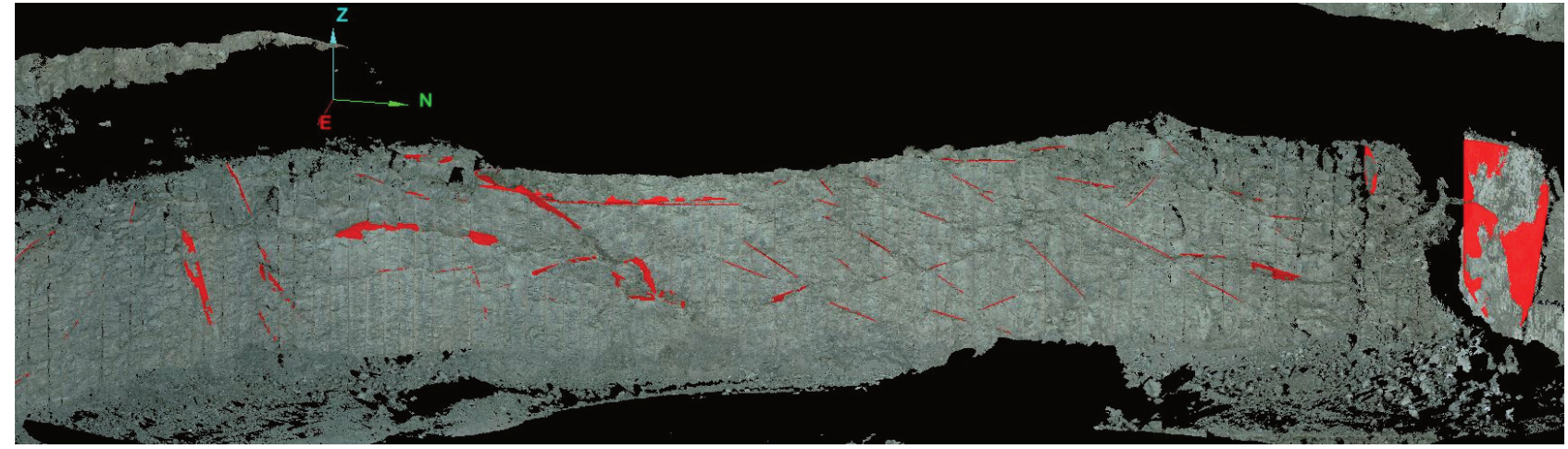

(c)

Figure 6 Software aided automated and semi-automated discontinuity analysis. (a) Resolution 8 point cloud before mapping; (b) Automatically mapped basalt face, different colours depict different joint sets; and (c) Manually mapped kimberlite face

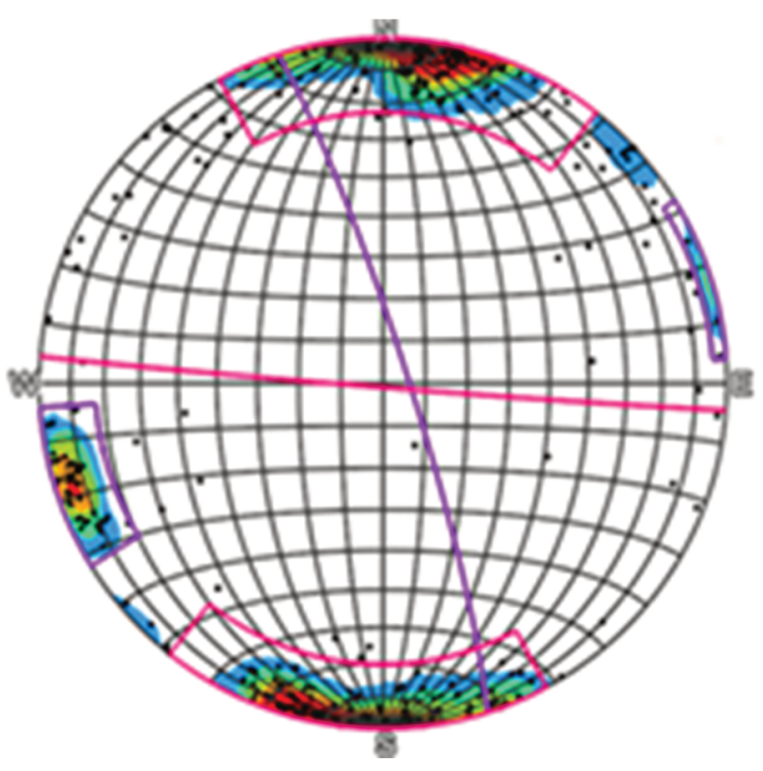

(a)

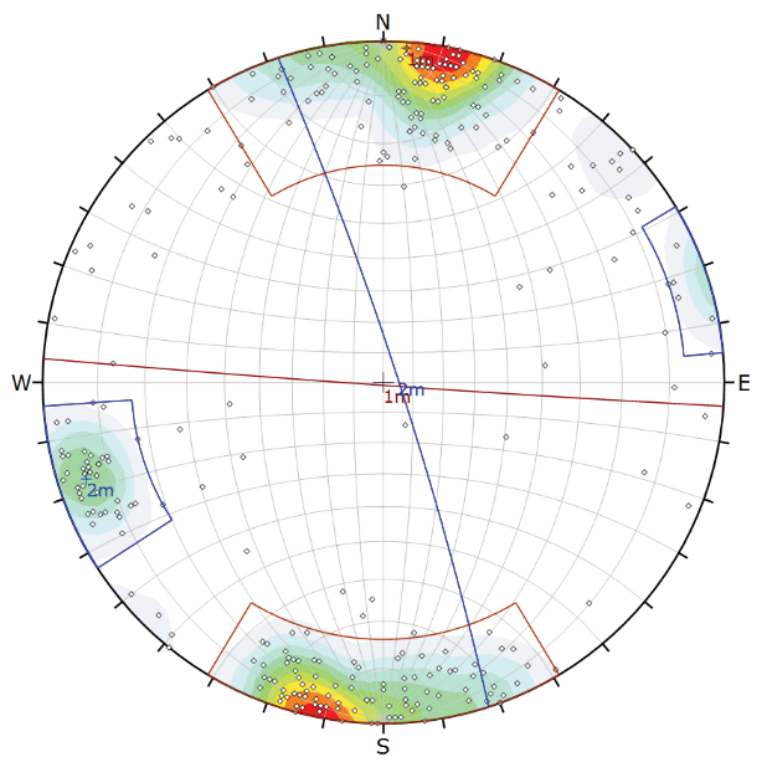

(b)

Figure 7 Stereographic projection of Satellite Pit north corner data. (a) PointStudio stereonet; and (b) DIPS stereonet 


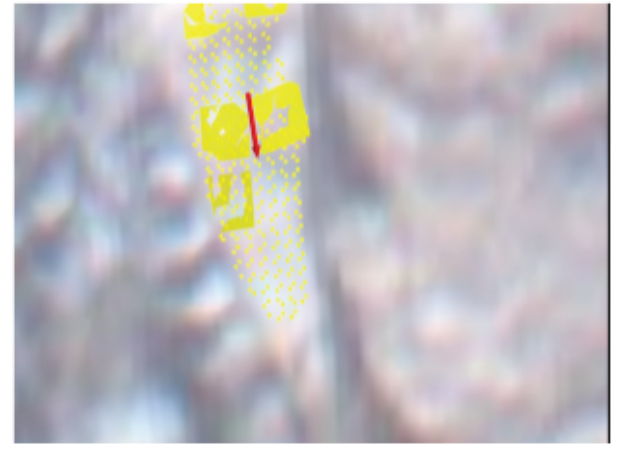

Dip: 76

Dip direction: 317

Subdivided into 6 chunks $1 \mathrm{~m}^{2}$ every $1 \mathrm{~m}$ Mean apparent dip: 73

Standard deviation: 3.3

(a)

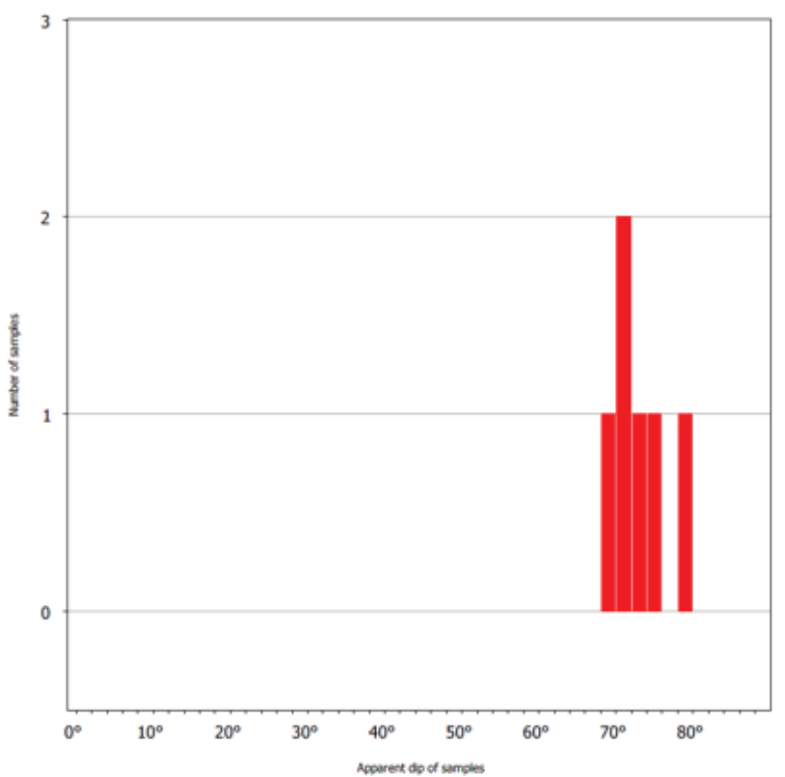

(b)

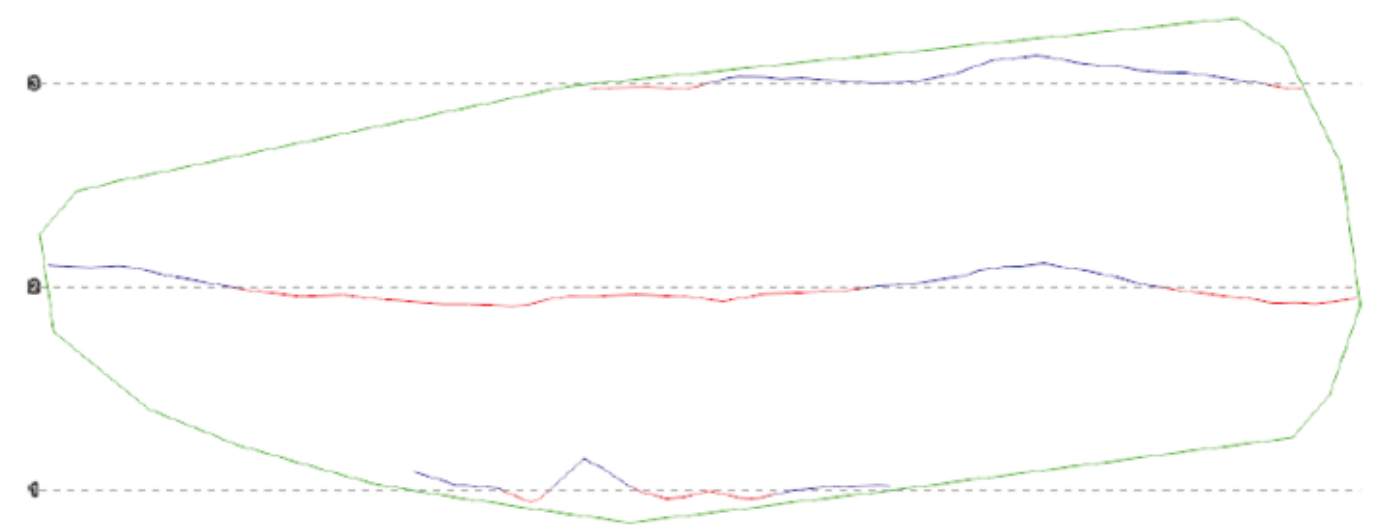

(c)

Figure 8 JRC estimation (a) Joint plane; (b) Apparent dip variations within the plane; and (c) Joint plane cross-section

\subsection{Kinematic analysis}

Kinematic analysis is frequently used in the analysis of rock slope stability to determine the possible modes of failure. The data from the northern corner of Satellite Pit was used to undertake kinematic analysis to determine the possible modes of failure. Potential mechanism of failure was determined by analysing the relationship between the major joint sets/planes of individual joints, the slope and basic friction angle. Table 2 shows all the potential modes of failure. Figure 9 shows the bench scale planar analysis.

Table 2 Possible modes of failure

\begin{tabular}{llll}
\hline & Planar failure (\%) & Wedge failure (\%) & Toppling failure (\%) \\
\hline Bench $\left(90 / 181^{\circ}\right)$ & 31 & 45 & 27 \\
Inter-ramp $\left(67 / 181^{\circ}\right)$ & 0.6 & 2.2 & N/A \\
\hline
\end{tabular}

The kinematic analysis failure results indicate that the possible localised failures are restricted to bench scale and the inter-ramp failure is not likely. 


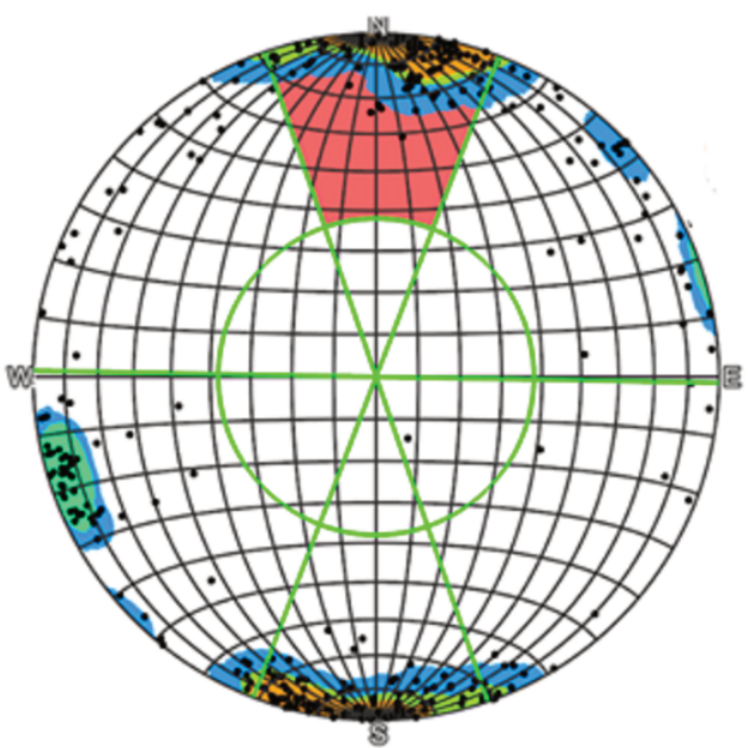

$\begin{array}{lr}\text { Slope orientation } & \\ \text { Dip } & 90^{\circ} \\ \text { Dip direction } & 181^{\circ} \\ \text { Strike } & 91^{\circ} \\ \text { Kinematic analysis properties } & \\ \text { Polar friction angle } & 38^{\circ} \\ \text { Lateral limit angle } & 20^{\circ}\end{array}$

$\begin{array}{cccc}\text { Set } & \text { Critical points } & \text { Total points } & \% \\ \text { All } & 99 & 315 & 31.4\end{array}$

Figure 9 Bench scale planar failure analysis

The data from the analysis can now be used in limit equilibrium and numerical modelling packages for detailed slope stability analysis.

\subsection{Mapping for blasting}

Mapping of blast blocks is vital for blast design to minimise highwall damage and to achieve controlled and desired fragmentation. At Letšeng, highwall control is of high priority because of the recently implemented steep slope, so every trim block is mapped and geological information is used for the blast design to minimise the highwall damage. Among the important factors that affect the blast integrity, geological defects and the rock mass strength play the major roles and must always be considered.

PointStudio has a function which can extrapolate joints throughout the trim blocks for blasting purposes. Figure 10 shows a block which was mapped and joints extrapolated throughout the block.

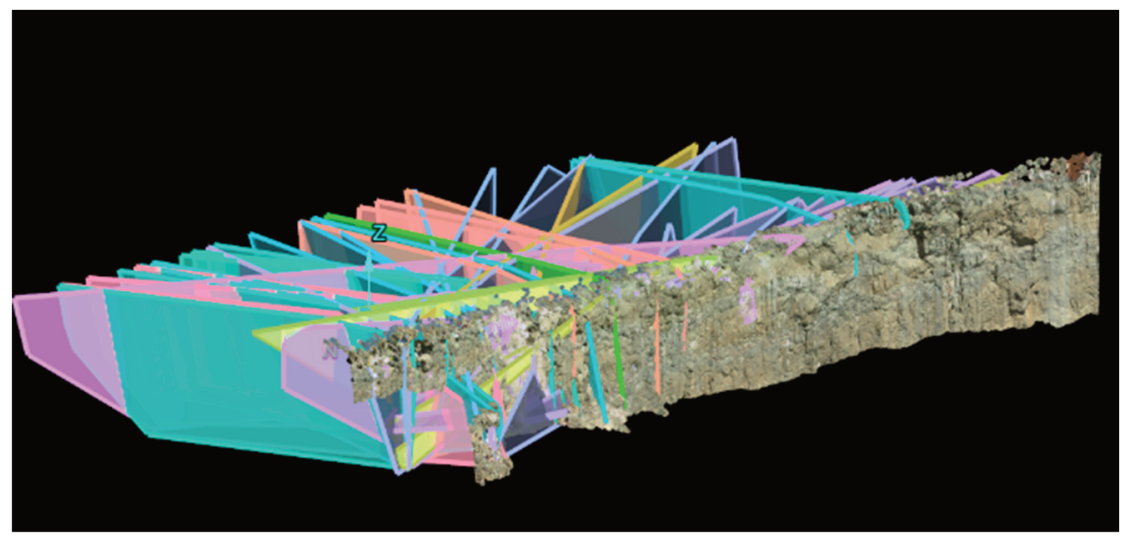

(a)

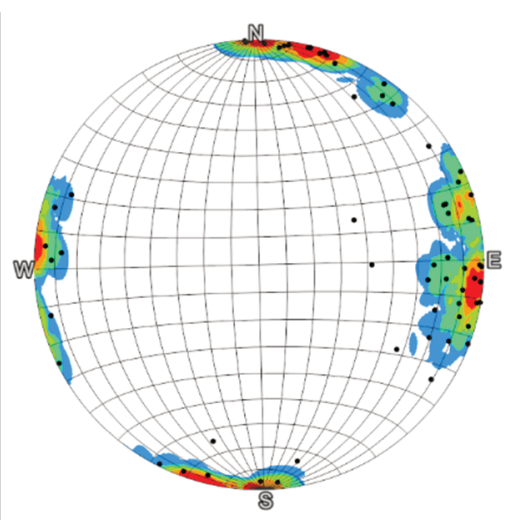

(b)

Figure 10 Face mapped for blasting. (a) Mapped face and extrapolated joints; and (b) Stereonet of the mapped joints 


\section{$4 \quad$ Monitoring}

\subsection{Slope deformation monitoring}

Mining companies have an obligation to support the best mining practices to ensure the safety of personnel. Slope failures are an unfortunate reality of open pit mining. A seemingly arbitrary combination of uncertain stresses, strains and volumetric changes could potentially be catastrophic even in mines with the most conservative slope designs. Within the context of open pit mining, best mining practices call for the timely detection of potential rock slope instabilities and effectively managing these instabilities once identified, making both strategic and tactical slope monitoring an integral part of any mine's slope monitoring program. Figure 11 shows the monitoring strategy implemented for Letšeng diamonds. Prisms are used for long-term deformation monitoring, Reutech radar is deployed in critical areas for tactical monitoring, and the Maptek laser scanner is applied for hazard identification (mapping), strategic monitoring and tactical monitoring.

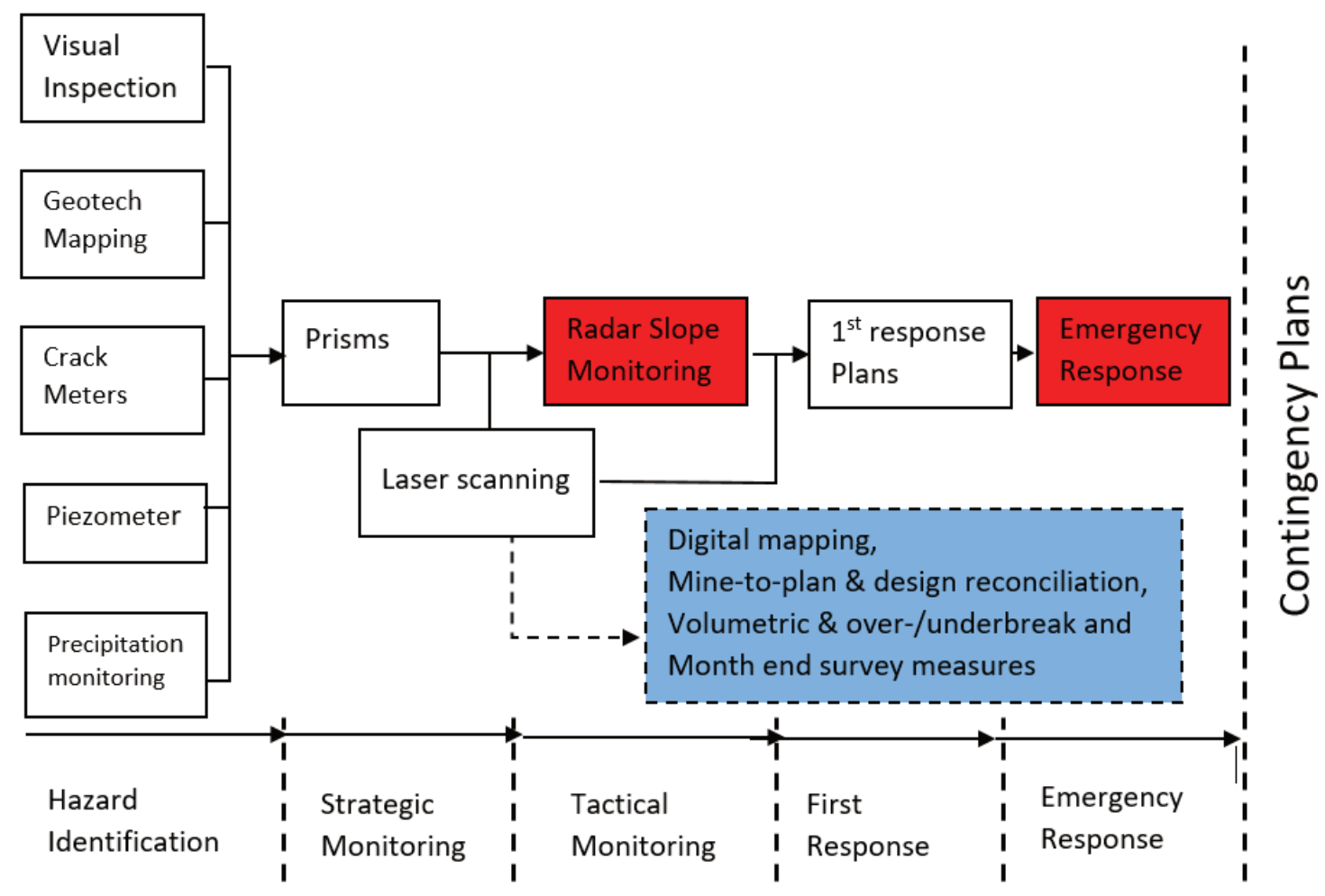

Figure 11 Monitoring strategy for Letšeng diamonds

In the case of the slope monitoring, the main purpose of geodetic measurement is to describe geometric changes. The issue of using terrestrial laser scanning to study the deformation process, which includes landslide movement, is based on performing scanning of an area threatened by deformation processes at successive time points (Bazarnik 2018). At the mine, the scanner is currently being used for both the periodic monitoring and continuous monitoring. In periodic monitoring, the scans must be taken from the fixed point. Since Maptek Sentry uses cells not points, the redeployment of the scanner must be in the same position and face in the same direction (i.e. zero orientation) as the previous setup. Therefore, beacons are constructed strategically around the pits (Figure 12(a)). The scans are taken from the same portion with the same backsight and imported into Sentry office software for data processing and analysis.

Continuous monitoring is conducted using Sentry (Maptek 2020b) field software hosted in the Sentry DMS system in a deployable trailer (Figure 12(b)). The DMS comprises a Maptek XR3 laser scanner, built-in tripod, solar panels, weather station, standby generator and wifi antenna mast for communications. The trailer is reversed to a desired location for monitoring; the laser scanner is mounted to a tripod and connected to the trailer with cables. The portable computer tablet assists in setting up parameters such as monitoring window and point density (usually resolution 8). Depending on the target to be monitored, the system can be directed 
to accept first, last or best (strongest) return signal. In cases of monitoring through mesh, last return signal is preferred in order to monitor slope face, not the mesh. The scans are downloaded automatically into the built-in computer for processing. Displacement, velocity, moisture intensity and inverse velocity time graphs are some of the output data that can be presented from monitoring data. Additionally, the behaviour of each graph can be related to environmental factors such as rainfall, wind direction and intensity. Trigger alarms can also be set and notifications sent through local mine networks.

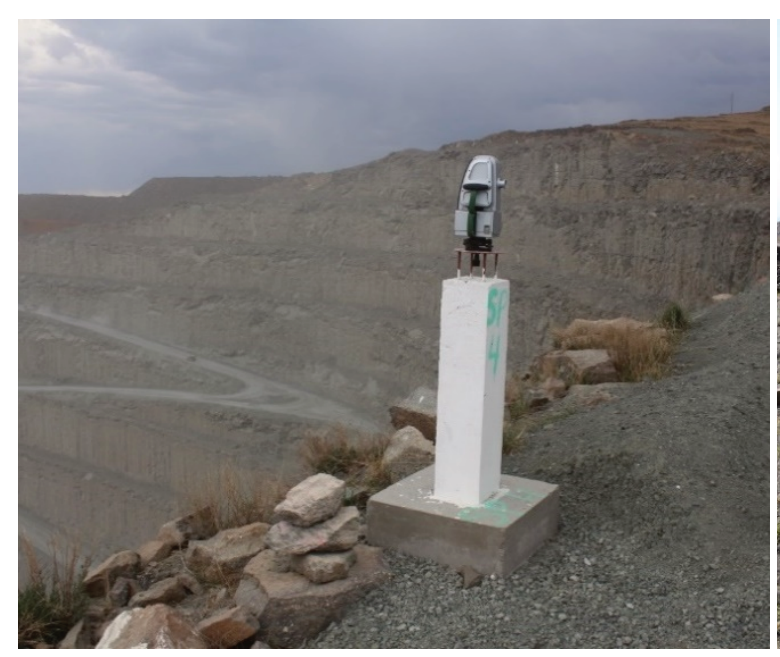

(a)

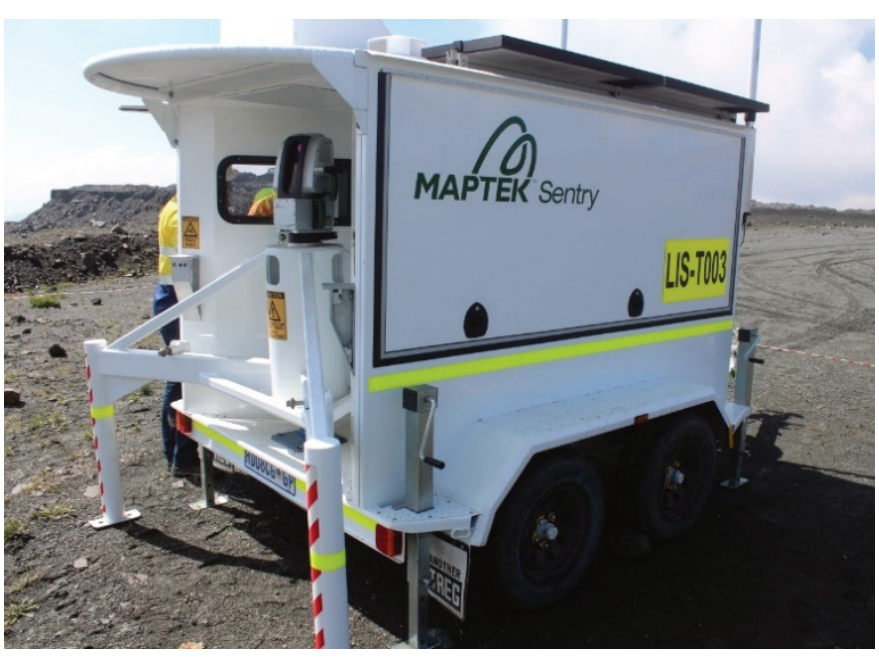

(b)

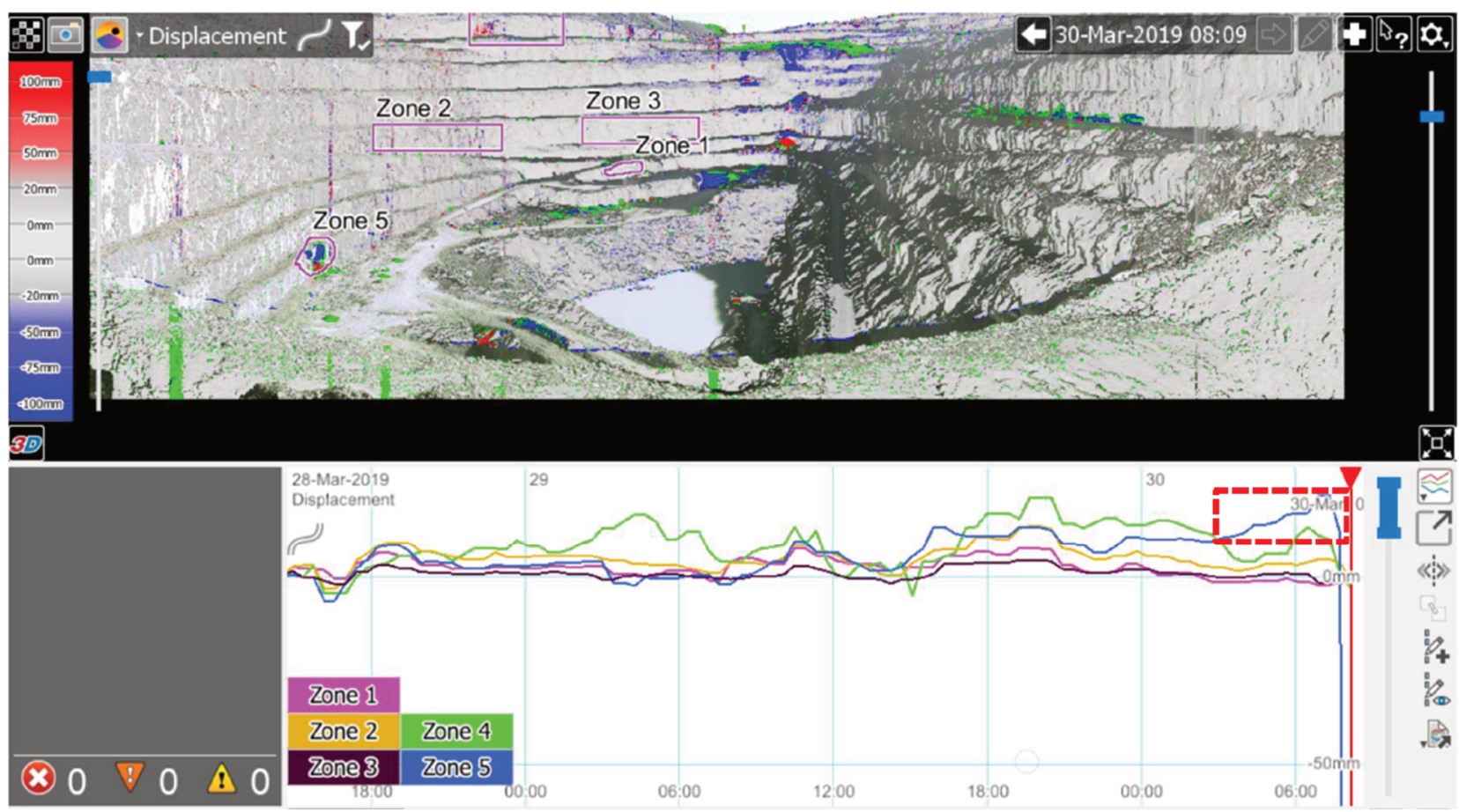

(c)

Figure 12 Slope deformation monitoring. (a) Fixed point monitoring station; (b) Sentry DMS trailer; and (c) Monitoring results showing pit faces, selected zones and graphs from respective zones

\subsection{Slope geometry reconciliation}

Benches are the fundamental building blocks of the pit slope and their geometry and behaviour often control the inter-ramp and hence the slope design. Because of that, systematic documentation and evaluation of the performance of benches becomes an important component of slope assessment programs. Letšeng has 
implemented rigorous quality control and quality assurance on the highwalls to ensure that the required catchment is achieved.

3D point cloud data is used in the assessment of the benches and the slope used. The data is used to compare the actual slope to the design and this exercise quantifies the frozen toes as well as the crest damage. The eliminations of frozen toes and the crest compliance is vital towards catch capacity of the catch berms. The crest compliance is calculated by comparing actual crestline and design crestline, while the toes are determined by comparing the actual bench face with the design face. Figure 13 shows the assessed face and the occurrence of frozen toes (depicted in yellow and red). Figure 14 shows crest compliance using PointStudio software. An intensive rock barring is performed on the crest above where the crest has been severely compromised beyond an allowable $10 \mathrm{~m}$.
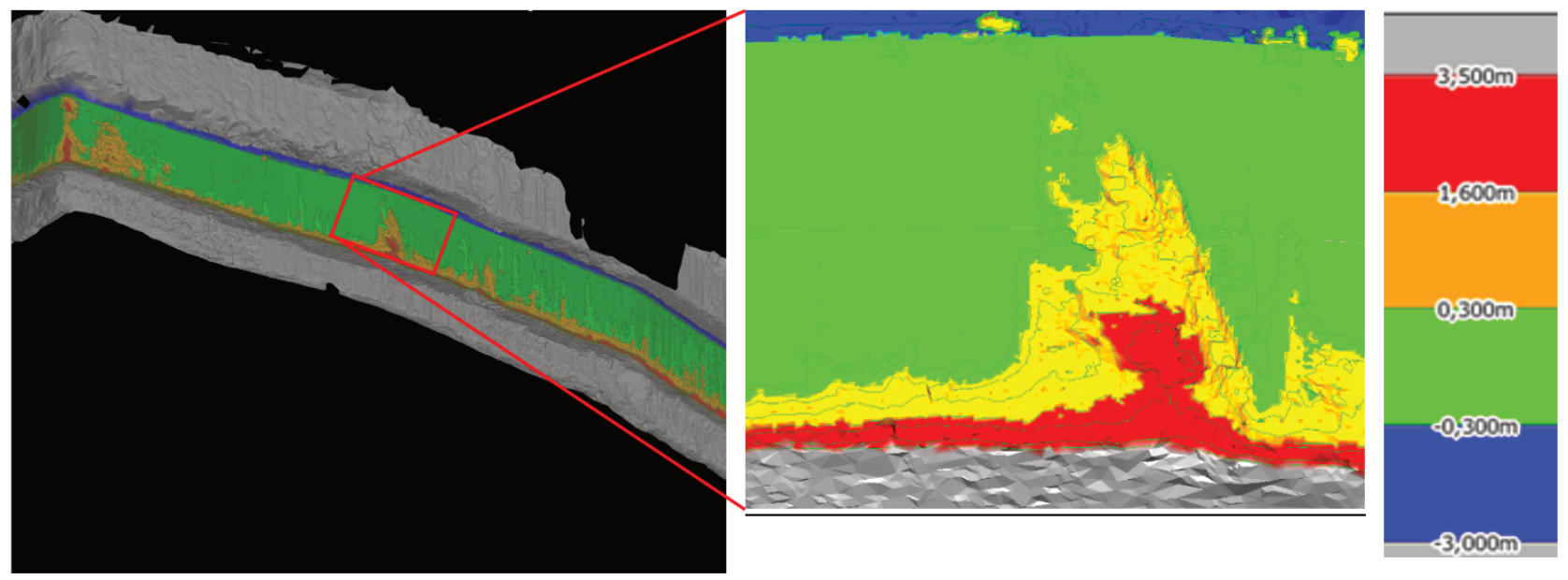

Figure 13 Frozen toe depicted by yellow and red colours

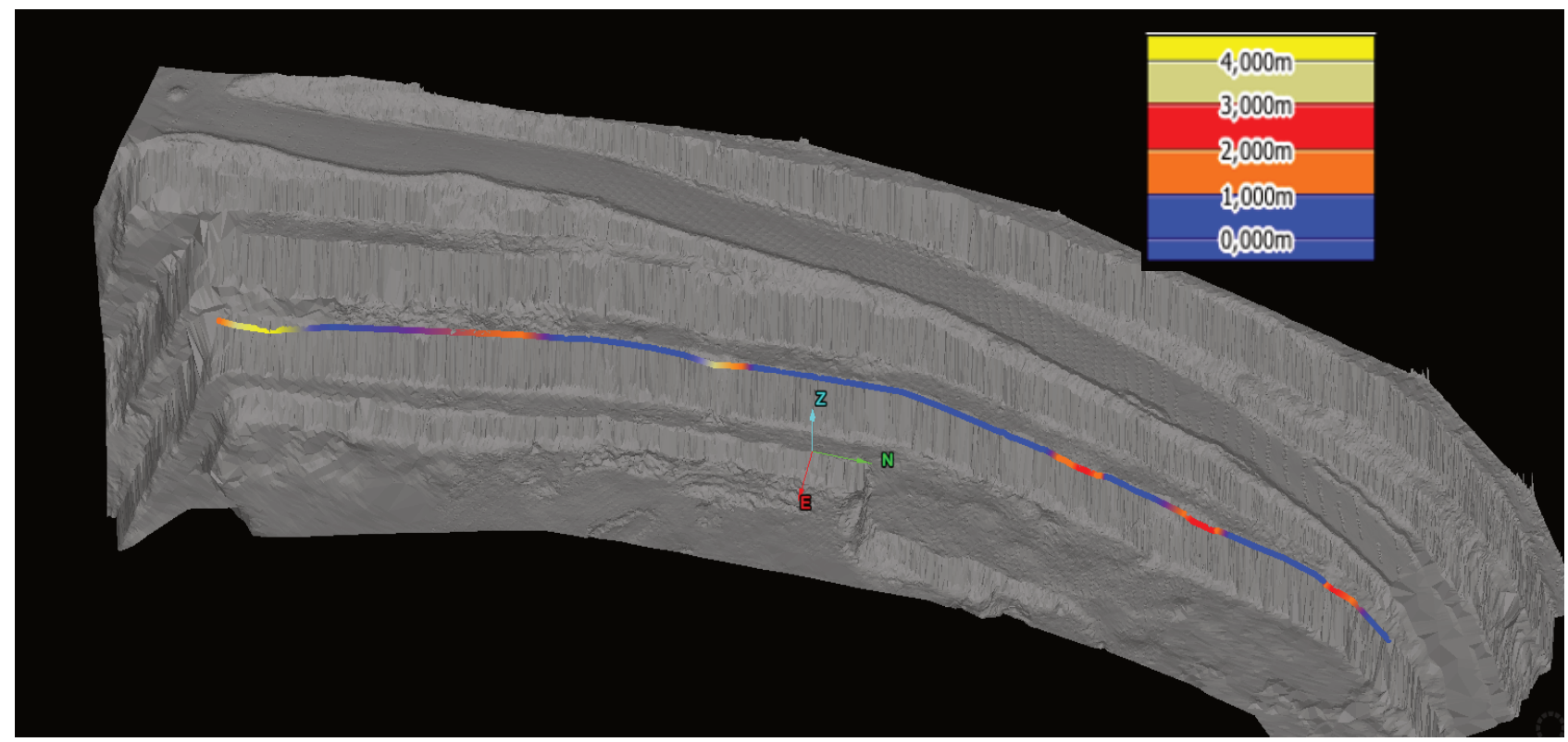

Figure 14 Crest compliance

The overall slope compliance is assessed in PointStudio using the built-in compliance module. The cross-sections of the actual slope are overlain on the designed slope to study the difference (Figure 15). 


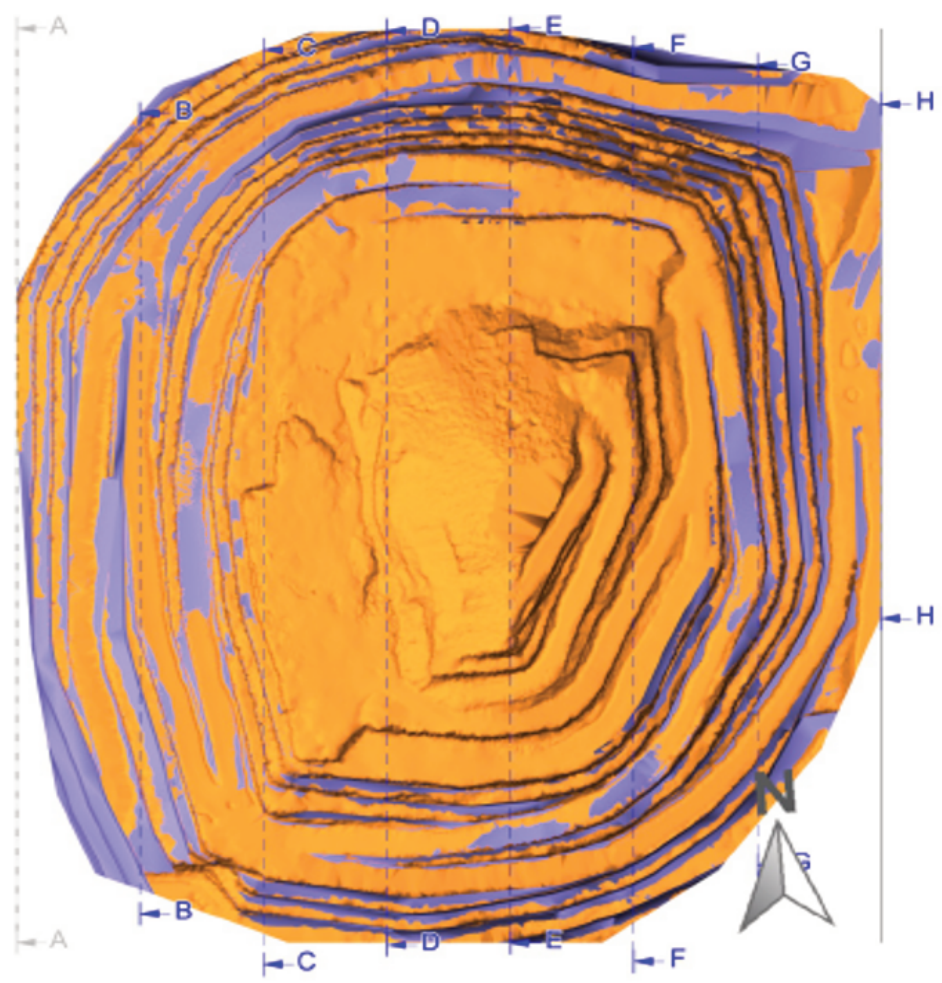

(a)
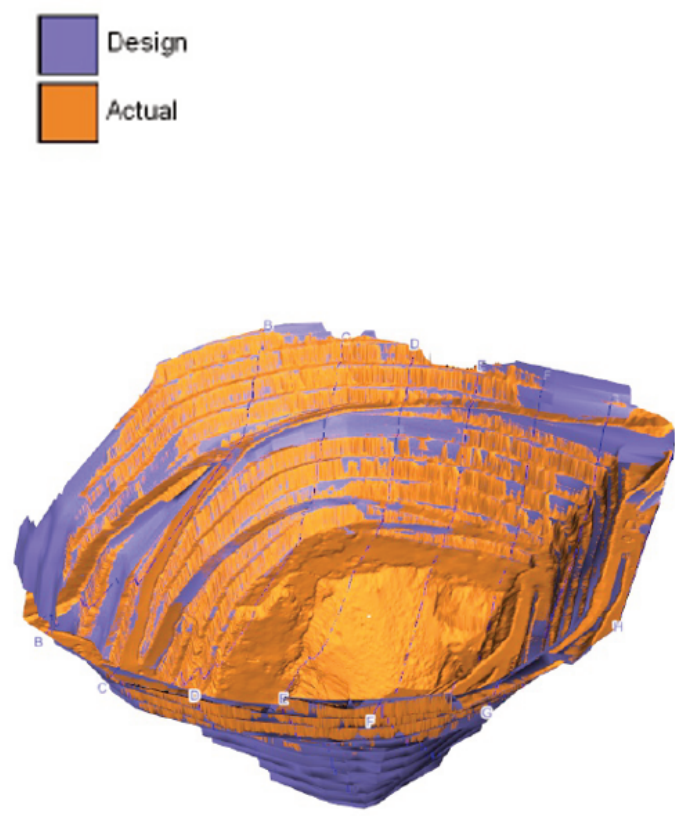

(b)

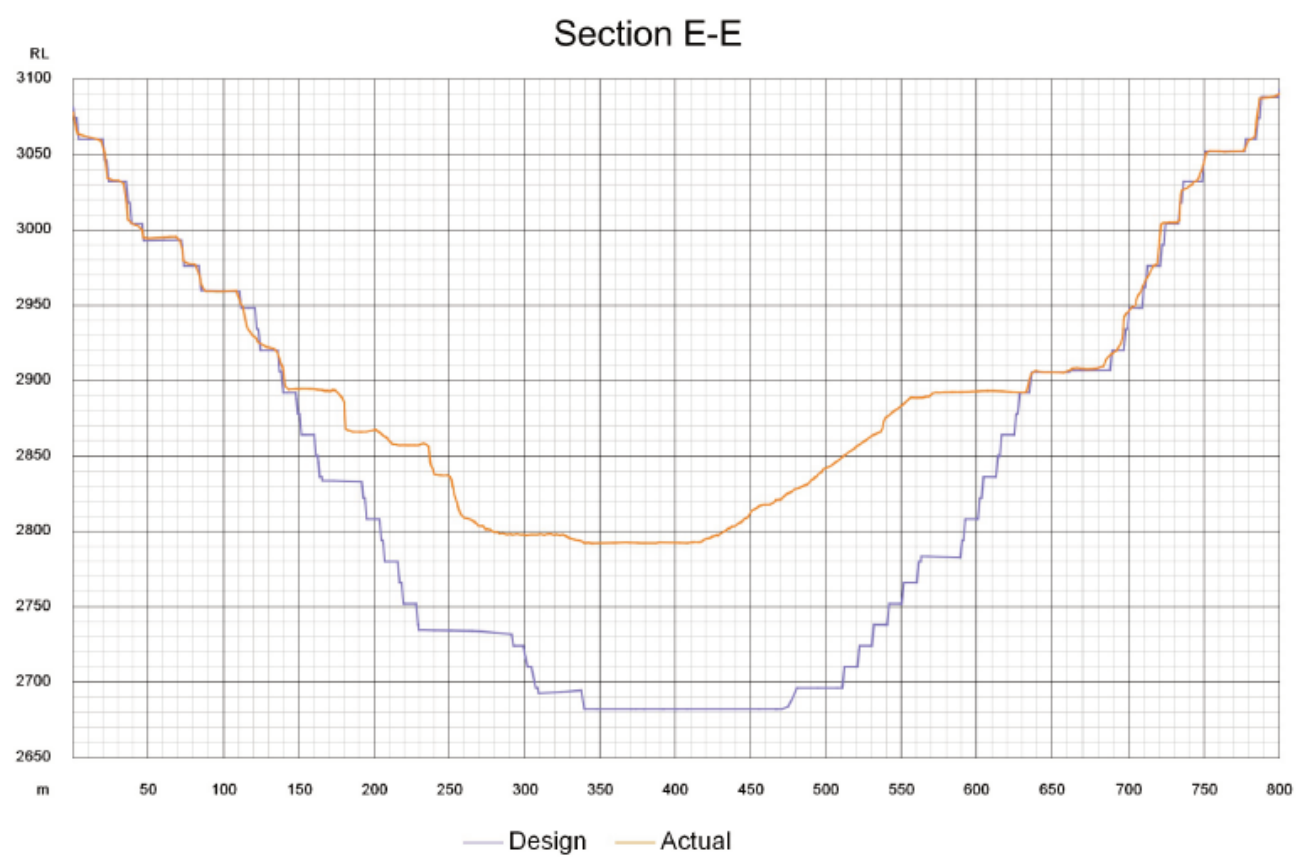

(c)

Figure 15 Conformance analysis. (a) Satellite Pit plan view; (b) Perspective view; and (c) EE cross-section

\section{Conclusion}

Time-of-flight laser scanning technology is currently used in geological environments for various applications. The system is used for volumetric measurements, geotechnical data collection and slope monitoring. The 3D laser scanner mapping is fast and efficient as it creates high resolution 3D point cloud data covering large areas in a couple of minutes. The geotechnical engineers can now collect significantly large datasets more 
safely and use the smart geotechnical tools to characterise geological defects and determine the possible failure modes. Additionally, the technology is applicable in slope deformation monitoring as well as mining compliance measurements.

\section{References}

Abellan, A, Jaboyedoff, M, Oppikofer, T \& Vilaplana, JM 2009, 'Detection of millimetric deformation using terrestrial laser scanner: experiment and application to a rockfall event', Natural Hazards and Earth System Sciences, vol. 9, 365-372.

Barton, N \& Bandis, S 1982, 'Effects of Block size on the Shear Behaviour of Jointed Rock', Proceedings of the 23rd Symposium on Rock Mechanics, American Institute of Mining, Metallurgy \& Petroleum Engineers, New York, pp. 739-760.

Bazarnik, M 2018, 'Slope stability monitoring in open pit mines using 3D terrestrial laser scanning', Proceedings of the $4^{\text {th }}$ International Conference on Applied Geophysics, vol. 66, https://doi.org/10.1051/e3sconf/20186601020

Beraldin, JA 2004, 'Integration of laser scanning and close range photogrammetry - the last decade and beyond', in O Altan (ed.), Proceedings of the XXth ISPRS Congress, International Society for Photogrammetry and Remote Sensing, pp. 972-983

Bohler, W \& Marbs, A 2002, '3D scanning instruments', Proceedings of the CIPA WG 6 International Workshop on Scanning for Cultural Heritage Recording, ZITI, Thessaloniki, pp. 9-18.

Bowen, D, Ferraris, RD, Palmer, CE \& Ward, JD 2009, 'On the unusual characteristics of the diamonds from Letseng-la-terae kimberlites, Lesotho', Lithos, vol. 112, pp. 767-774, https://doi.org/ 10.1016/j.lithos.2009.04.026

Buckley, SJ, Howell, JA, Enge HD \& Kurz, TH 2008, 'Terrestrial laser scanning in Geology: data acquisition, processing and accuracy considerations', Journal of the Geological Society, vol. 165, issue 3, pp. 625-638.

Bye, AR \& Bell, FG 2001, 'Stability assessment and slope design at Sandsloot open pit, South Africa', International Journal of Rock Mechanics and Mining Sciences, vol. 38, pp. 449-466.

Hetman, CM, Smith, BS, Robey, J, Nkotsi, T, Mohapi, M \& Mohapi, T 2018, 'Letšeng diamond mine, Lesotho: a variant of Kimberleytype pyroclastic kimberlite emplacement', Mineralogy and Petrology, vol. 112, issue 2, pp. 365-382.

International Society for Rock Mechanics 1978, 'Suggested methods for the quantitative description of discontinuities in the rock masses', International Journal of Rock Mechanics and Mining Sciences \& Geomechanics Abstracts, vol. 15, pp. 219-368.

Maptek 2019, Scanners - general information - Supplementary Data, viewed 2 September 2019, https://sites.google.com/a/maptek.com.au/i-site-documents/engineering-docs/general-information/88xx-data/1-e2-spotand-separation

Maptek 2020a, Maptek PointStudio, computer software, https://www.maptek.com/products/pointstudio/index.html

Maptek 2020b, Maptek Sentry, computer software, https://www.maptek.com/products/sentry/index.html

Nguyen, HT, Fernandez-Steeger, TM, Wiatr, T, Rodrigues, D \& Azzam, R 2011, 'Use of terrestrial laser scanning for engineering geological applications on volcanic rock slopes - an example from Madeira island (Portugal)', Natural Hazards and Earth System Sciences, vol. 11, pp. 807-817.

Oppikofer, T, Jaboyedoff, M, Blikra, L, Derron, MH \& Metzger, R 2009, 'Characterization and monitoring of Aknesusisng terrestrial laser scanning', Natural Hazards and Earth System Sciences, vol. 9, 633-653.

Parisean, WG 2006, Design Analysis in Rock Mechanics, Taylor \& Francis, Leiden.

Priest, SD 1993, Discontinuity analysis for Rock Engineering, Chapman and Hall, London.

Rosser, NJ, Petly, DN, Lim, M, Dunning, SA \& Allison, RJ 2005, 'Terrestrial laser scanning for monitoring the process hard rock coastal cliff erosion', Quarterly Journal of Engineering Geology and Hydrogeology, vol. 38, pp. 363-375.

Scott Smith, BH, Nowicki, TE, Russell, JK, Webb, KJ, Mitchell, RH, Hetman, CM... \& Robey, JvA 2013, 'Kimberlite Terminology and Classification', Proceedings of the 10th International Kimberlite Conference, vol. 2, pp. 1-17.

Slob, S, Hack, V, van Knapen, B, Turner, K \& Kemeny, JM 2005, 'A method for automated discontinuity analysis of rock slopes with 3D laser scanning', Proceedings of the Transportation Research Board 84 ${ }^{\text {th }}$ Annual Meeting, Transportation Research Board, Washington DC, pp. 187-194

Slob, S \& Hack, R 2004, '3D terrestrial laser scanning as a new field measurement and monitoring technique', in R Hack, R Azzam \& R Charlie (eds), Engineering Geology for Infrastructure Planning in Europe, Springer, Berlin, https://doi.org/ 10.1007/978-3540-39918-6_22

Stanley, JR, Flowers, RM \& Bell, DR 2015, 'Erosion patterns and mantle sources of topographic change across the Southern African Plateau derived from the shallow and deep records of kimberlites', Geochemistry, Geophysics, Geosystems, vol. 16, issue 9, pp. 3235-3256, https://doi.org/10.1002/2015GC005969

Strang, DR 2010, Engineering geological characterisation and slope stability assessment of Whitehall Quarry, MSc Thesis, University of Canterbury, Waikato.

Sturzenegger, M \& Stead, D 2009, 'Close-range terrestrial digital photogrammetry and terrestrial laser scanning for discontinuity characterisation on rock cuts', Engineering Geology, vol. 106, issue 3-4, pp. 163-182, https://doi.org/ 10.1016/j.enggeo.2009.03.004 